\title{
Inmigración europea, artesanos y talleres en la temprana industrialización del Uruguay, 1870-1914
}

Alcides Beretta Curi*

Recibido: julio de 2014

Aprobado: septiembre de 2014

Resumen: El artículo analiza el sector de los artesanos y los talleres en el Montevideo de la modernización, situando esta perspectiva en el contexto de los grandes cambios y problemas que se presentaron en Europa y la América Latina. A su vez, presenta este proceso como resultado de una creciente presencia de inmigrantes europeos, de modo que se reconoce en ellos el rol de agentes innovadores en los procesos de modernización que vivió entonces el Uruguay.

Palabras claves: artesanos, inmigrantes, talleres, industrias, Montevideo, siglo XIX.

\section{European immigration, craftsmen and workshops in the early industrialization of the Uruguay, 1870-1914}

Abstract: The article analyses the sector of craftsmen and workshops at Montevideo of modernization, placing this perspective in the context of major changes and problems that arose in Europe and Latin America. At the same time, it presents this process as a result of a growing presence of European immigrants, so that is recognized in them the role of innovative actors in the processes of modernization that lived then the Uruguay.

Key Word: craftsmen, immigrants, workshops, industries, Montevideo, 19th century.

* Profesor Titular en régimen de dedicación total en el Centro de Estudios Interdisciplinarios Latinoamericanos "Profesora Lucia Sala” de la Facultad de Humanidades y Ciencias de la Educación, Universidad de la República, Uruguay. alcides.berettacuri@gmail.com

EL TALLER DE LA HISTORIA, vol. 6, n. o 6, 2014, págs. 247-275. Issn: 1657-3633; e-Issn:2382-4794. Programa de Historia, Facultad de Ciencias Humanas, Universidad de Cartagena de Indias, Colombia 


\section{1.- Modernización y desarrollo capitalista: crisis de los gremios y el artesanado}

Estados e Ilustración acumularon fuertes críticas al régimen gremial y al artesanado, y se elaboraron proyectos diversos para modificar y hasta suprimir los primeros. Sin embargo, como señalan Epstein y Prak, en las últimas décadas, los estudios sobre los gremios cuestionan la incidencia negativa de los mismos e incluso, se los reconoce como instituciones capaces de hacer lugar para la innovación en el proceso que conducía a la revolución industrial. ${ }^{1}$ En Europa, si bien el sistema artesanal reaccionó con un "blindaje" temporal ante innovaciones que se percibían como amenazas, no es menos cierto que en el largo plazo fue capaz de generar innovaciones mediante inventos propios. ${ }^{2}$

En América Latina, el artesanado y los gremios transitaron la crisis del régimen colonial con diversas dificultades; y constituidos los Estados nacionales, se encontraron en escenarios fuertemente imbuidos por el pensamiento liberal. La aplicación de ese pensamiento liberal en materia económica (librecambio) generó protestas y acciones violentas de los artesanos durante el siglo XIX, en la mayoría de los países latinoamericanos, particularmente señalados en México, Perú, Chile y Colombia. Si bien esas políticas liberales no afectaron por igual a todos los artesanos, a la reivindicación del "proteccionismo" se sumaron reclamos por el costo más elevado de la canasta familiar, las condiciones de vida y de trabajo, el acceso a una educación técnica, los derechos del ciudadano, entre otras. ${ }^{3}$ Los nuevos Estados

1 S. R. Epstein, Maarten Prak, Guilds, Innovation, and the European Economy, 140o-18oo, New York, Cambridge University Press, 2008.

2 Helga Schultz, Historia económica de Europa, 150o-18oo. Artesanos, mercaderes y banqueros, Madrid, Siglo XXI, 2001, p.89.

3 Existe una extensa bibliografía sobre artesanos y gremios en América Latina. Respecto a algunos de los problemas señalados ver: Adriana López Monjardin, "El artesano urbano a mediados del siglo XIX", en Anuario II, Veracruz, Universidad Veracruzana, 1979, pp.55-63; Sonia Pérez Toledo, "Una organización alternativa de artesanos: la Sociedad Mexicana Protectora de Artes y Oficios, 18431844" en Signos Históricos n. ${ }^{\circ}$ 9, México D. F., UAM-Iztapalapa, 2003, pp.73-100; Miguel Orduña Carson, "Artesanos de la ciudad de México en la segunda mitad del siglo XIX: luchas de resistencia en el marco de la hegemonía”, en Travesía n. ${ }^{\circ} 10-11$, San Miguel de Tucumán, Universidad Nacional de Tucumán, 2008-2009, pp.101-120; Renán Vega Cantor, "Liberalismo económico y artesanado en la Colombia decimonónica”, en Boletín Cultural y Bibliográfico vol.xxvII, n. ${ }^{\circ} 22$, , Bogotá, Biblioteca Luís Ángel Arango, 1990, pp.47-65; Roicer Flórez Bolívar y Sergio Paolo Solano, "Educando al buen ciudadano. Las guardias nacionales en la Provincia de Cartagena, Colombia, 1832-

Dossier: Artesanos: formas de trabajo, sociabilidades, movilidad social y cultura política en Hispanoamérica, siglos XVI-XX 
surgidos de las guerras de independencia adoptaron normativas que condujeron a la desarticulación de los gremios, quedando los artesanos "librados individualmente a nuevas formas de contratación jornalera -cuando no destajista- y sin mecanismos legales y colectivos de negociación", en tanto el "maestro" en muchos casos se convirtió en el patrón capitalista. ${ }^{4}$

El impulso al libre comercio mediante el Arancel de 1821, instaló la polémica entre proteccionistas y librecambistas en México, a la vez que generó la firme resistencia de los artesanos, particularmente los hiladores y tejedores de Puebla 5 a la que se sumaron más tarde los agricultores algodoneros. Las contradicciones de los gobiernos federales, entre proteger la producción nacional y las necesidades fiscales, alternaron encuentros y tensiones con los artesanos. Subyacía tras el conflicto, el camino a transitar desde la producción artesanal y el sistema gremial hacia la moderna industria. ${ }^{6}$ Las políticas librecambistas en Perú encontraron dificultades para su implementación desde 1821, representando las tarifas de 1840 el primer intento serio de aplicarlas, aunque su efecto fue limitado en la práctica. En diciembre de 1858, el gremio de carpinteros y otros artesanos realizaron violentas protestas contra la importación de diversos artículos, en un episodio contra la política

1857”, en Anuario de Estudios Americanos, vol.67, n. ${ }^{\circ}$ 2, Sevilla, EEHA, 2010, pp.605-633; Sergio Paolo Solano, "El mundo del trabajo urbano en el Caribe colombiano durante el siglo XIX", en José Polo y Sergio Paolo Solano (eds.), Historia social del Caribe colombiano, Medellín, Universidad de Cartagena/La Carreta Editores, 2011, pp.73-122; Iñigo García-Bryce "Politics by Peaceful Means: Artisan Mutual Aid Societies in Mid-Nineteenth-Century Lima, 1860-1879", in The Americas, vol.59, n. ${ }^{\circ}$, Washington D. C., Academia Histórica de la Orden Franciscana, 2003, pp.325-345; Paul Gootenberg, "The Social Origins of Protectionism and Free Trade in Nineteenth-Century Lima”, in Journal of Latin American Studies, vol.14, n. ${ }^{\circ}$, Durham, Duke University, 1982, pp.329358; M. A. Illanes "La revolución solidaria. Las sociedades de socorros mutuos de artesanos y obreros: un proyecto popular democrático, $1840-1887$ ", en Polis vol.1, n. ${ }^{\circ}$, Santiago de Chile, Universidad Bolivariana, 2003, pp.1-63; Sergio Grez Toso, "Los artesanos chilenos del siglo XIX: un proyecto modernizador-democratizador", en Cyber Humanitatis n. ${ }^{\circ} 41$, Santiago de Chile, Universidad de Chile, 2007. www.archivochile.com/Ideas_Autores/grezs/grezso019.pdf.

4 Clara E. Lida, "Trabajo, organización y protesta artesanal: México, Chile y Cuba en el siglo XIX”, en Historia Social n. ${ }^{\circ} 31$, Valencia, Instituto de Historia Social 1998, p.68

5 En 1823, según el informe presentado por la Junta Nacional Instituyente, había registrados 50 mil tejedores en Puebla.

6 Lilia Carbajal Arenas, "Los artesanos de Puebla y el arancel de 1821”, en Análisis Económico vol. XXVIII, n. ${ }^{\circ} 68$, México D. F., UAM-Azcapotzalco, 2013, pp.135-154. 
librecambista que reconocía antecedentes desde la independencia de España. ${ }^{7} \mathrm{El}$ ingreso de manufacturas europeas y norteamericanas en Chile, provocó la crisis de algunos sectores de artesanos que no se encontraron en condiciones de competir. El descontento plasmó en algunas reivindicaciones bajo los términos "protección a la industria nacional", siendo las primeras en expresarse las ramas del cuero y calzado (1826) y las de ebanistas y fabricantes de muebles (1829). ${ }^{8}$

\section{El taller artesanal en América Latina}

En la ciudad de México el pequeño taller "era mayoritario dentro del mundo de la producción manufacturera, donde los establecimientos fabriles o los talleres de gran tamaño no eran muchos, ni existían en todas las ramas. La fuerza de trabajo se encontraba pulverizada en una inmensa lista de oficios que, aunque especializados, tendían a perder su cualificación en medio de un crónico desempleo". ${ }^{9}$ En 1865, el $20 \%$ de los establecimientos correspondían a la rama textil, segunda en importancia luego de la tabacalera, coexistiendo organizaciones productivas del período colonial con trabajo domiciliario, talleres y medianas empresas. ${ }^{10}$ México fue definiendo con contradicciones, avances y retrocesos, una política proteccionista, distanciándose de otros países latinoamericanos.

Tempranamente, en los nuevos estados hispanoamericanos, el capital mercantil local -a veces extranjero- concurrió a erosionar la organización artesanal y prepararon, el advenimiento de establecimientos modernos. Supuestamente, quedaba abierto el camino para el desarrollo de las industrias, que las elites dirigentes identificaron con el progreso. Trujillo Bolio observa que en México coexistieron

7 Iñigo García-Bryce, "Politics by Peaceful Means: Artisan Mutual Aid Societies in MidNineteenth-Century Lima, 1860-1879”, in The Americas vol.59, n. ${ }^{\circ} 3$, Washington, D. C., Academia Histórica de la Orden Franciscana, 2003, pp.325-345.

8 Sergio Grez Toso, "La reivindicación proteccionista artesanal y la constitución del movimiento popular (Chile, 1826-1855)", en Historia Social n. ${ }^{\circ} 31$, Valencia, Instituto de Historia Social, 1998, pp.89-99.

9 Sonia Pérez Toledo y Carlos Illades, "el artesanado textil de la ciudad de méxico durante el siglo XIX" en Historia Social n. ${ }^{\circ}$ 31, Valencia, Instituto de Historia Social, 1998, p.77

10 Mario Trujillo Bolio, Empresariado y manufactura textil en la ciudad de México y su periferia, México D. F., Siglo XIX/CIESAS, 2000.

Dossier: Artesanos: formas de trabajo, sociabilidades, movilidad social y cultura política en Hispanoamérica, siglos XVI-XX 
formas diversas de producción (taller, manufactura, trabajo a domicilio) y que en algunos talleres el maestro se había convertido en propietario y contrataba mano de obra asalariada. ${ }^{11}$ Esta situación se registró en varias repúblicas hispanoamericanas, y ha sido tema de debate las posibilidades del tránsito del taller artesanal a la empresa fabril y el devenir del maestro en agente capitalista y embrión de una burguesía industrial. ${ }^{12}$

Durante los tres siglos de dominio colonial talleres y gremios se multiplicaron en el mundo hispanoamericano, y el número de artesanos fue relativamente elevado en las nuevas repúblicas. Gazmuri estima -en base a diversas fuentes y el censo de 1854-, que a mediados del siglo xIX el número de varones artesanos en Santiago de Chile era algo mayor a los 6.000 individuos. ${ }^{13}$ Para otras ciudades hispanoamericanas también las estimaciones son altas. Cartagena, según el censo de 1777 registraba 1.125 artesanos que representaban el 22,4\% de la población económicamente activa. En el censo poblacional y ocupacional de 1871, el sector artesanal en el Estado Soberano de Bolívar representaba el 11\% de su población económicamente activa (PEA), inferior a los registrados en los Estados de Antioquia (13\%), Boyacá (14\%), Cauca (25\%), Cundinamarca (20,1\%), Santander (39\%) y Tolima (27\%). ${ }^{14}$ Bogotá contaría a mediados del XIX con unos 4.000 artesanos ${ }^{15} \mathrm{y}$, en 1870, las pesonas dedicadas a las prácticas artesanales representaban algo menos del $23 \%$ de la población colombiana, con una participación muy elevada de las mujeres. ${ }^{16}$ La ciudad de México contaba con unos 11.200 artesanos, según el registro

11 M. Trujillo, Empresariado y manufactura textil en la ciudad de México y su periferia.

12 Ver por ejemplo Gabriel Salazar, "Industrialización popular en Chile: perfil del empresariado plebeyo (1823-1885)", en Encuentros Latinoamericanos vol.vi, $\mathrm{n}^{0}{ }_{1}$, Montevideo, Universidad de la República, 2012, pp.129-171; R. Vega Cantor, "Liberalismo económico y artesanado en la Colombia decimonónica”, pp.47-65.

13 Cristián Gazmuri, El 48 chileno, Santiago, Ed. Universitaria, 1998, 215 pp.

14 Sergio Paolo Solano, "El mundo del trabajo urbano en el Caribe colombiano durante el siglo XIX", pp.78, 81

15 Jaime Jaramillo Uribe, "Las sociedades democráticas de artesanos y la coyuntura política y social colombiana de 1848", en Anuario Colombiano de Historia Social y de la Cultura n. ${ }^{\circ}$, Bogotá, Universidad Nacional, 1976, pp.5-18.

16 Jorge Orlando Melo, "La evolución económica de Colombia, 1830-1900", en Manual de Historia de Colombia, Bogotá, Instituto Colombiano de Cultura, 1979, pp.133-207. 
de $1842 .{ }^{17}$ Definitivamente, los artesanos constituían un sector significativo de la población urbana en varias ciudades hispanoamericanas. Sus dificultades para sobrevivir luego de la crisis colonial, les llevó a desarrollar diversas estrategias, buscar alianzas e influir en fracciones de las clases dirigentes que buscaban ampliar sus cuotas de poder. Estas circunstancias fueron aprovechadas por los artesanos para la construcción de ciudadanía y ampliación de los derechos electorales. ${ }^{18}$

En el Río de la Plata las organizaciones gremiales fueron muy débiles, y casi inexistentes en Montevideo. Esta ciudad fue fundada tardíamente, a inicios del siglo XVIII, coincidiendo con el movimiento reformista que en la metrópoli abogaba por la supresión de los gremios. Este contexto concurrió a que el trabajo del artesano fuera relativamente libre, débilmente sujeto a reglamentaciones y su nivel de vida desahogado por la escasa competencia. Aun en los casos que el artesano era esclavo, la percepción de un salario permitió a algunos, con ingentes penurias, comprar más tarde su libertad. ${ }^{19}$

\section{Inmigración europea, artesanado e industria}

Entre 1870 y 1913 emigraron alrededor de 60 millones de europeos, que se orientaron hacia distintas geografías. Si bien cobraron relevancia Estados Unidos y Australia, en las últimas décadas del XIX el principal destino fue la América del Sur y en ella, el Río de la Plata. Se estiman los saldos netos en unos 4 millones para Argentina y 2 millones para Brasil, e inferiores para Chile (200.000), Cuba y Uruguay (600.00o en cada país). ${ }^{20}$ En la primera mitad del XIX emigraron del Reino Unido y

17 Sonia Pérez Toledo, Los hijos del trabajo. Los artesanos de la ciudad de México, 1780-1853, México D. F., Universidad Autónoma Metropolitana/El Colegio de México, 1996, 300 pp.

18 Roicer Flórez Bolívar, Sergio Paolo Solano y Jairo Álvarez Jiménez, "Liberalismo, ciudadanía y vecindad en Nueva Granada (Colombia) durante la primera mitad del siglo XIX", en Tempo n. ${ }^{\circ} 32$, Rio de Janeiro, Universidade Federal Fluminense, 2012, pp.163-192.

19 Lucía Sala, Nelson de la Torre y Julio Carlos Rodríguez, Estructura económico-social de la colonia, Montevideo, Eds. Pueblos Unidos, 1967, pp.137-140; Nelson Pierrotti, "La enseñanza de los oficios en el Montevideo colonial (1726 - 1830)”, en Páginas de Educación vol.2, n. ${ }^{\circ} 2$, Montevideo, Universidad Católica de Uruguay, 2009, pp.115-134.

20 Nicolás Sánchez-Albornoz, "La población de América Latina, 1850-1930", en Lesli Bethell (ed.), Historia de América Latina. 7 América Latina: economía y sociedad, c. 1870-1930, Barcelona, Ed. Crítica, 1991, pp.112-113. 
Alemania, también de Escandinavia y otros países del noroeste europeo. Desde la década de 1880 es claro el predominio de italianos, españoles y portugueses, y hacia fines del ochocientos se incorporaron a esa corriente, austrohúngaros, rusos y polacos. ${ }^{21}$ También fue significativo el flujo de retorno.

O’Rourke y Williamson argumentan que la hambruna y la revolución europea probablemente activaron el primer gran flujo de migraciones masivas en la década de 1840 pero "fueron los fundamentos económicos subyacentes los que hicieron que cada flujo fuera mayor que el anterior, y así hasta la primera guerra mundial". ${ }^{22}$ En Europa escaseaban los recursos naturales pero abundaba la fuerza de trabajo, en tanto Argentina, Australia, Brasil, Canadá, Estados Unidos y Nueva Zelanda, disponían de importantes recursos naturales pero carecían del contingente de trabajadores necesario. Las disparidades en materia de ingresos per cápita entre los países europeos periféricos y Australia, Canadá, Estados Unidos y otros países de la América Latina en el período 1870-1913, se convirtieron en un incentivo considerable para las migraciones transatlánticas. En 1913, el ingreso per cápita de Argentina era alrededor de un 30\% superior a los de España e Italia. Por consiguiente, este factor generó fuertes incentivos económicos para emigrar hacia Argentina. Uruguay también tenía ingresos por persona superiores a los de España e Italia, y Chile prácticamente se encontraban al mismo nivel de estos dos países europeos. ${ }^{23}$

En Argentina, entre 1871 y 1914 ingresaron 5.917.259 personas, de las cuales 2.722.384 retornaron a sus países de origen y 3.194.875 permanecieron en el país de adopción. El impacto de estas cifras se registró en las provincias del litoral pampeano (Capital Federal, Buenos Aires, Córdoba, Santa Fe y Entre Ríos: por ejemplo, en las dos últimas el crecimiento de la población fue de 909 por ciento y de 216,8 por ciento respectivamente). Ezequiel Gallo aprecia que la entrada masiva de inmi-

21 Kevin H.O’Rourke y Jeffrey G. Williamson, Globalización e historia: la evolución de la economía atlántica en el siglo XIX, Zaragoza, Prensas Universitarias de Zaragoza, 2006, p.162.

22 Para los Estados Unidos se estima que, entre 1890 y 1914, retornó aproximadamente el 30\% de ese flujo en términos brutos: 50\% para los italianos y españoles, pero menor para los irlandeses y los escandinavos. No afectó por igual a todos los países: por ejemplo, entre mediados del XIX e inicios de la década de 1920, el retorno desde Argentina (italianos y españoles) fue de un 47\% respecto al flujo de entrada bruto en el país. K. O’Rourke y J. Williamson, Globalización e historia: la evolución de la economía atlántica en el siglo XIX, p.163.

23 Andrés Solimano, "Migraciones internacionales y mercado de trabajo globalizado: la experiencia latinoamericana”, en Revista de la CEPAL nº8o, Santiago de Chile, Cepal, 2003, pp.55-72. 
grantes "trastocó, en consecuencia, el equilibrio demográfico y regional” y concluye que el papel de los inmigrantes dentro de la estructura ocupacional fue "crucial y, posiblemente, sin parangón en el mundo". Gallo precisa que, a nivel empresarial el $68,4 \%$ de los propietarios de comercios, el $68,7 \%$ de los industriales y el $31,9 \%$ de los agropecuarios habían nacido fuera de la Argentina. ${ }^{24}$ En Chile, ${ }^{25}$ Brasil ${ }^{26}$ y Uruguay $^{27}$, los europeos impactaron en el medio urbano con la instalación de talleres y establecimientos fabriles.

Los estudios sobre artesanos, talleristas e industriales, reparan en el principal rol cumplido por los italianos y en segundo orden por otras nacionalidades, entre ellas los españoles. En cuanto a este colectivo, destacan los catalanes, en tanto a la inmigración de origen gallego se le ha asignado un desempeño relevante en el sector servicios. No obstante, estudios recientes reconocen una mayor presencia de la inmigración gallega en las actividades de transformación, como el estudio de Ruy Farías para el distrito de Barracas al Sud en la ciudad de Buenos Aires, ${ }^{28}$ de Pilar

24 Ezequiel Gallo, "Política y sociedad en Argentina, 1870-1916", en Lesli Bethell (ed.), Historia de América Latina. 10 América Latina: economía y sociedad, c. 1870-1930, pp.41-66.

25 Baldomero Estrada Turra, "Participación italiana en la industrialización de Chile. Orígenes y evolución hasta 1930", en Baldomero Estrada Turra (ed.), Presencia italiana en Chile, Serie Monografías Históricas, n. ${ }^{\circ}$, Valparaíso, Universidad Católica de Valparaíso, 1993, pp.89-123; Concepción Navarro Azcue y Baldomero Estrada Turra, "Migración y Redes de poder en América: el caso de los industriales españoles en Valparaíso (Chile) 1860-1930", en Revista Complutense de Historia de América vol.31, Madrid, Universidad Complutense, 2005, pp.115-146; Luigi Favero, et al, Il contributo italiano allo sviluppo del Cile, Torino, Fondazione Giovanni Agnelli, 1993, 470 pp.

26 Warren Dean, "Industriales y oligarquía en el desarrollo de San Pablo," en Mario Cerutti, y Menno Vellinga (comps.), Burguesías e industria en América Latina y Europa meridional, Madrid, Alianza Ed., 1989, pp.23-54; Vania Herédia, O processo de industrialização da zona colonial italiana: estudo de caso da primeira indústria têxtil do Nordeste do estado do Rio Grande do Sul, Caxias do Sul, Universidade de Caxias do Sul, 1997, 240 pp.

27 Raúl Jacob, Breve historia de la industria uruguaya Montevideo, Fundación de Cultura Universitaria, 1981, 155 pp.; Alcides Beretta Curi, "Emigración italiana y modernización en la periferia. Los italianos en la creación del sector industrial uruguayo (1870/1930)", en Studi Emigrazione n. ${ }^{\circ}$ 150, Roma, Centro Studi Emigrazione, 2003, pp.227-251; Alcides Beretta Curi, "L'immigrazione europea nella formazione del tessuto imprenditoriale: l'Uruguay e le nazioni circostanti (18701900)", en Studi-Emigrazione vol. XVIII, n. ${ }^{\circ}$ 184, Roma, Centro Studi Emigrazione, 2011, pp.675-695; Alcides Beretta Curi, "Del artesanado a los gremios industriales. Liberalismo y tensiones en la constitución de las primeras asociaciones patronales. El caso de la Liga Industrial (1879-1888)", en Revista de Ciencias Sociales, segunda época, n. ${ }^{\circ}$ 24, Quilmes, Universidad Nacional de Quilmes, 2013, pp.87-108.

28 Ruy Farías, "Peones, obreros y jornaleras: Patrones de asentamiento e inserción socioprofesional de los gallegos en Avellaneda y Lanús, 1890-1930", en Buenos Aires Gallega. Inmigración, pa- 
Cagiao ${ }^{29}$ y Alcides Beretta Curi respecto a algunas ramas (conservación de alimentos, panificación, bebidas, tabacos, imprenta y papelería, muebles y colchones, jabón, velas, confección de ropa, curtidos y calzados) ${ }^{30}$ en Montevideo.

\section{Inmigración europea y artesanado en Montevideo}

Constituido el Estado uruguayo, la información consular del Estado sardo, estimaba que era mayor la presencia de "italianos" en Montevideo luego de 1830 respecto a otras nacionalidades radicadas en la ciudad. La mayoría provenía de Génova. A ciertas ventajas que ofrecía la joven nación, se sumaba la inseguridad para los extranjeros en Buenos Aires durante los gobiernos de Juan Manuel de Rosas (18291832; y especialmente durante 1835-1852). Por otra parte, Montevideo no solo era una ciudad segura, sino que se presentaba para muchos emigrados franceses e italianos como una tierra de libertad, afín a las corrientes ideológicas que animaron las revoluciones de 1848 y las luchas de garibaldinos y mazzinistas en Italia. ${ }^{31}$ Oddone señala que en el período 1881-1901, ingresaron 51.466 italianos frente a 29.364 españoles. En tanto los ligures radicaron principalmente en la ciudad -por sus actividades navieras-, los piamonteses y lombardos escogieron la periferia urbana. En el tramo 1883-1890, fueron los italianos del sur quienes alimentaron una fuerte corriente inmigratoria. 32

La elevada presencia del binomio "inmigrante" y "artesano", puede seguirse

sado y presente, Buenos Aires, Comisión para la Preservación del Patrimonio Cultural de la Ciudad Autónoma de Buenos Aires, 2007.

29 Pilar Cagiao Vila, “La inmigración gallega en Uruguay (1870-1936)”, en Anuario Americanista Europeo $\mathrm{n}^{0} 3$, Salamanca, Redial/Cesial, 2005, pp.93-112.

30 Alcides Beretta Curi, Inmigración europea e industria. Uruguay en la región (1870-1915), Montevideo, Universidad de la República, 2014, 160 pp.

31 Juan A. Oddone, "Italians in Uruguay: Political Participation and Country Consolidation during Mass Immigration", in The Columbus People: Perspectives in Italian Immigration to the Americas and Australia Wiley Online, vol.11, n. ${ }^{\circ} 3$, Library Special 1994 .

32 Juan A. Oddone, La Emigración Europea al Río de la Plata, Montevideo, Eds. de la Banda Oriental, 1966, 112 pp. 
desde diversas fuentes. Urta, ${ }^{33}$ a partir de expedientes matrimoniales de las décadas de 1830-1860, al analizar las declaraciones de los testigos constata un elevado número de extranjeros, quienes ejercían oficios y trabajaban como asalariados o patrones. Es igualmente ilustrativo al respecto, el estudio realizado por Caraballo y Sagaseta desde la compulsa de 1.600 expedientes matrimoniales (años 1870 a 1872) en el Archivo Parroquial de la Iglesia Matriz. El análisis de la documentación aporta nuevos elementos al conocimiento de la mano de obra disponible en Montevideo. En un total de 2.950 declaraciones de los testigos, respecto a sus ocupaciones laborales, cerca de 1.000 se identificaron como artesanos o desempeñándose en actividades artesanales. La mayoría eran inmigrantes europeos -predominando los italianos, españoles y franceses- que trabajaban como carpinteros, zapateros y albañiles, entre otras profesiones declaradas. ${ }^{34}$

Sin duda, la sociedad montevideana de mediados del XIX no era una sociedad tradicional: su tardía formación durante la colonia, el menor peso de la esclavitud en la producción, y los tempranos y crecientes flujos inmigratorios -de los países vecinos, Argentina y Brasil, pero fundamentalmente europeos-, la moldearon como más abierta y moderna. Por otra parte, el impacto de la inmigración europea fue más rápido y profundo que en otras sociedades contemporáneas de América Latina, por tratarse de una sociedad poco estructurada y en proceso de transformación. Pellegrino y Camou, caracterizan la sociedad montevideana nativa como muy joven y afectada por "catástrofes" (un prolongado conflicto bélico, la Guerra Grande entre 1839 y 1851; una epidemia de fiebre amarilla que eliminó el 10\% de la población). En base a dos fuentes documentales: a) un padrón nominal que registra las casas de la ciudad y sus habitantes y b) el censo de 1860, Camou y Pellegrino

33 Gimena Urta, “Artesanos, comerciantes y los orígenes de la industria (1830-1860)", versión borrador del trabajo preparado en el seminario de investigación del Centro de Estudios Interdisciplinarios Latinoamericanos "Profa. Lucía Sala", Facultad de Humanidades y Ciencias de la Educación, Universidad de la República.

34 Dahiana Caraballo y Graciana Sagaseta, "Los aportes de los Sistemas de Información Geográfica en la investigación histórica. El sector de la madera y el calzado en Montevideo a fines del siglo XIX", (trabajo monográfico realizado en el seminario de investigación "Inmigración europea y artesanado: entre la protesta popular y los primeros programas industrialistas en América Latina (1870/190o)" segundo semestre de 2012 (Centro de Estudios Interdisciplinarios Latinoamericanos Prof ${ }^{a}$. Lucía Sala" (CEIL) Facultad de Humanidades y Ciencias de la Educación, Universidad de la República. 
determinan que la presencia de los inmigrantes se aproximaba a la mitad de sus habitantes (49,6\% según el padrón; 47,8\% según el censo). ${ }^{35}$

Gráfico 1

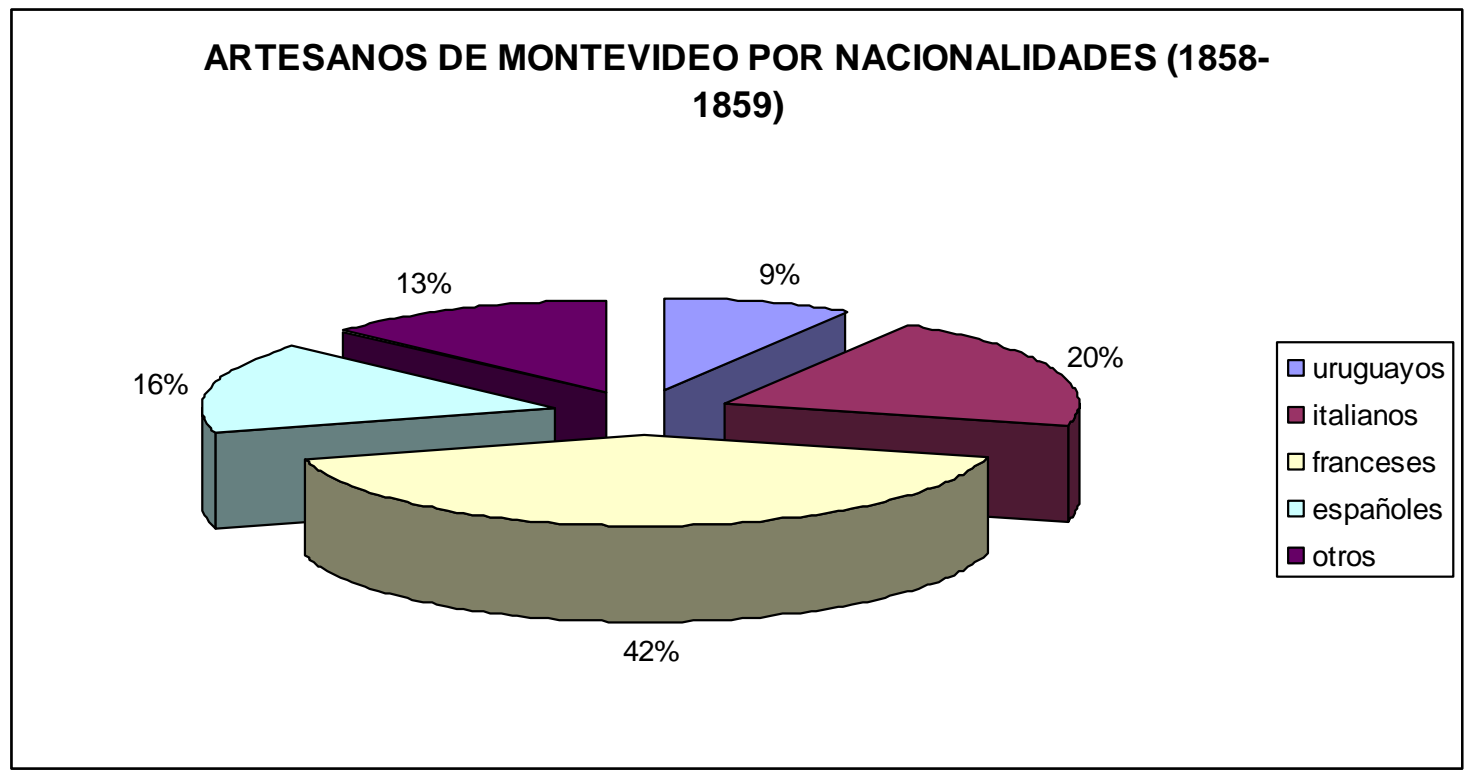

Fuente: elaboración propia a partir de María Camou y Adela Pellegrino, "Una fotografía instantánea de Montevideo".

Estas autoras observan que los artesanos, al igual que en otras ciudades latinoamericanas, anexaban en sus talleres la actividad comercial, en tanto vendían los artículos que producían. No obstante, no es posible en base a esas fuentes determinar quienes eran propietarios de su taller, quienes mano de obra asalariada, o bien si se trataba de trabajadores independientes sin local propio. La PEA masculina ascendía en Montevideo a 4.136 personas, de las cuales los artesanos representaban el 18\%. Esta categoría se distribuía por nacionalidades del siguiente modo: 7,1\%

35 María Camou y Adela Pellegrino, "Una fotografía instantánea de Montevideo", en Ediciones del V Centenario, tomo 2, Montevideo, Universidad de la República, 1992, pp.135-136 
uruguayos; $15,8 \%$ italianos, $39,8 \%$ franceses, $13,9 \%$ españoles y $15,5 \%$ pertenecían a otras nacionalidades). 36

Por otra parte, los registros de población son ilustrativos al respecto. El censo de Montevideo de 1884 estaría dando cuenta de unos 7.00o trabajadores independientes que el relevamiento no los reconoce como "establecimientos" y que constituían unidades productivas unipersonales o estrictamente familiares de carácter artesanal. ${ }^{37} \mathrm{El}$ censo de Montevideo de 1889 establecía una población de 215.061 habitantes, de los cuales eran extranjeros 100.739 (46,84\%). Si esos datos se circunscribían a los hombres extranjeros mayores de 20 años, la cifra se eleva a 53.109, representando el 78,6\% de los efectivos masculinos. En 1908, los hombres extranjeros mayores de 20 años eran 46.631 y representaban en Montevideo el $52,75 \%$ de esa categoría. ${ }^{38}$

Definitivamente, el desarrollo de actividades como el artesanado y la industria se encontraban, desde mediados del siglo "Una fotografía instantánea de Montevideo"y al menos hasta la primera guerra mundial, en manos de extranjeros, mayoritariamente europeos. Por otra parte, aunque no es posible precisarlo ya que los censos no lo registran, debe estimarse que una proporción significativa de quienes eran censados como artesanos o industriales "uruguayos" pertenecían a la primera o segunda generación de uruguayos nacidos en un hogar constituido por uno o dos progenitores extranjeros, y continuaban al frente de los talleres iniciados por sus padres.

36 M. Camou y A. Pellegrino, "Una fotografía instantánea de Montevideo”, p.146

37 Julio Millot y Magdalena Bertino, Historia económica del Uruguay, tomo II 186o-191o, Montevideo, FCU, 1996, 470 pp.

38 Silvia Rodríguez Villamil y Graciela Sapriza, La inmigración europea en el Uruguay. Los italianos, Montevideo, Eds. de la Banda Oriental, 1982, 150 pp.

Dossier: Artesanos: formas de trabajo, sociabilidades, movilidad social y cultura política en Hispanoamérica, siglos XVI-XX 


\section{Montevideo y el taller artesanal}

Uruguay no sufrió del mismo modo la crisis del artesanado y los gremios. Recordemos que los ya citados historiadores Sala, Rodríguez y de la Torre señalan su débil desarrollo y el escaso peso de los artesanos en la vida político-social tanto en la colonia como una vez creada la República Oriental del Uruguay. ${ }^{39}$ Estudios más recientes precisan la existencia de cierta diversidad de talleres y aun de gremios, favorecidos por la actividad del puerto de Montevideo. ${ }^{40}$

La multiplicación de los talleres luego de 1830 está claramente asociada a la creciente presencia de la inmigración europea. ${ }^{41}$ En las dos décadas siguientes, franceses e italianos, en menor proporción, españoles y alemanes -aunque no únicamente-, desarrollan diversas actividades destinadas en su casi totalidad al mercado urbano: carpinterías y mueblerías, zapaterías, imprentas y litografías, grabado en vidrio, marmolerías, herrerías y herrerías artísticas, fundiciones, talleres de costura y sastrerías, entre otras actividades.

La revolución parisina de 1848 y las represiones desencadenadas por la segunda república francesa, tanto en la capital como en provincias, y en otros Estados europeos, determinaron la huída de numerosos artesanos hacia diversos destinos, siendo uno de los principales la América Latina. Alucinados por la "causa", allí se convirtieron en agentes de la revolución internacional, panfletarios, editores de periódicos y propagadores del utopismo, y cumplieron un importante rol en el desarrollo de un pensamiento social, más teórico que aplicado, y no pocas veces un tanto desencontrado con las realidades latinoamericanas. ${ }^{42}$ Terceros se alistaron en las filas de los trabajadores y concurrieron al desarrollo de diversas expresiones solidarias y de lucha, desde el mutualismo a la constitución de organizaciones de

39 L. Sala, N. de la Torre y J. C. Rodríguez, Estructura económico-social de la colonia.

40 Nelson Pierrotti, "La enseñanza de los oficios en Montevideo colonial (1726 a 1830)" pp.115-133; Arturo Bentancur, El Puerto colonial de Montevideo, Montevideo, Facultad de Humanidades y Ciencias de la Educación, 2 tomos, 1998-1999, 424 pp. y 390 pp.

41 L. Sala y E. Alonso, El Uruguay comercial, pastoril y caudillesco. Tomo II: Sociedad, política e ideología.

42 Pierre-Luc Abramson, Las utopías sociales en América Latina en el siglo XIX, México, Fondo de Cultura Económica, 1999, 407 pp. 
clase, que se proponían metas más ambiciosas como la transformación de la sociedad. Desde otra perspectiva y rastreando los orígenes de la actividad industrial en América Latina, observamos que numerosos exiliados usufructuando sus experiencias laborales y sus conocimientos en diversos oficios, concurrieron a la instalación de talleres y pequeñas empresas en los países donde radicaron. En Montevideo esa actividad fue muy importante y ha sido posible identificar a varios de estos agentes de la república y el socialismo como propietarios de talleres. De esta forma, alimentaron los procesos de diferenciación social que condujeron, poco más tarde, a la formación de una burguesía industrial a la que se incorporaron antiguos artesanos.

Acompañando el desempeño agro-exportador de Uruguay, desde la década de 1870 se registra un crecimiento de la actividad industrial, preferentemente a cargo de talleres y medianas empresas. En la década de 1880 se modernizan los molinos harineros, en 1898 se instala la primera textil y en 1904, el primer frigorífico. Entonces, los establecimientos fabriles eran pocos y a la escala de un pequeño país, ya que a excepción de los frigoríficos -rápidamente controlados por el capital anglo-norteamericano- esta industria realizaba escasas exportaciones.

Clara E. Lida precisa que tanto en el mundo europeo como en el americano, el término "artesano" ha referido a "formas de trabajo y modos de producción previos a la revolución industrial y propios de las corporaciones gremiales del antiguo régimen". ${ }^{43}$ Pero lo que singulariza el caso uruguayo en el escenario latinoamericano, es que se trata de una actividad que tiene débiles raíces en el pasado colonial y por lo tanto debe considerarse como relativamente nueva. Pese a cierta pervivencia de elementos precapitalistas, en las dos últimas décadas del siglo XIX, un sector de talleres de Montevideo se despegó del conjunto, originando pequeñas empresas con características crecientemente capitalistas, y regladas por las leyes del mercado.

Caracteriza a estos talleres el ser una unidad de producción individual, que utilizaba mano de obra familiar y, paulatinamente, incorporó mano de obra asalariada. En el espacio del taller dominaron la manualidad y la herramienta. La legislación proteccionista (leyes de 1875, 1886, 1888, 1912), estimuló su multiplicación, a la vez que algunos incorporaron máquinas (en rol de herramientas complejas) sin modificar sustancialmente su estructura productiva: la máquina era allí una he-

43 C. E. Lida, “Trabajo, organización y protesta artesanal: México, Chile y Cuba en el siglo XIX”, p.67

Dossier: Artesanos: formas de trabajo, sociabilidades, movilidad social y cultura política en Hispanoamérica, siglos XVI-XX 
rramienta más (picadoras de tabaco en las cigarrerías, máquinas de coser en los talleres de costura, sierras accionadas a vapor en carpinterías, etc.). Cuando la acumulación y la demanda del mercado lo permitieron, se ampliaba el local, se incorporaban asalariados, pero el taller conservaba en esencia su estructura artesanal, abriendo oportunidades a cierta división del trabajo. Pese a estas novedades y este crecimiento, el hombre dominaba el proceso productivo en su totalidad, ya que está en la base de este proceso, el conocimiento de oficios. La producción era pequeña y estaba destinada al mercado interno, principalmente urbano y de la capital-puerto, Montevideo.

Este escenario motiva una primera pregunta respecto a cómo fue posible que en Montevideo, y teniendo en cuenta ese débil antecedente colonial, se registrara un tan rápido desarrollo de talleres y pequeñas empresas. Una economía agroexportadora en expansión y el crecimiento demográfico -resultado de una sociedad que atemperó sus índices de mortalidad y recibió un flujo inmigratorio relativamente sostenido- generaron indudablemente un escenario propicio. La respuesta parece encontrarse en la inmigración europea que ofreció una alta disponibilidad de mano de obra con niveles importantes de cualificación en oficios, el desarrollo de destrezas y habilidades adquiridas previamente en talleres y establecimientos industriales en Europa, y una mentalidad con niveles de racionalidad e iniciativa, propios de las sociedades modernas. Las estrategias familiares para emigrar, los valores de que fueron portadores los inmigrantes (contracción al trabajo, altos niveles de autoexigencia para alcanzar las metas propuestas, el ahorro y la capacidad de iniciativa) les hizo funcionales a una sociedad que avanzaba rápidamente por la senda del capitalismo.

La reconstrucción de historias y trayectorias empresariales, revela que la mayoría de estos inmigrantes procedían de regiones y ciudades con actividad artesanal o que estaban transitando la revolución industrial. Inmigrantes alemanes e ingleses en Montevideo, reconocen su origen o su formación, en las zonas más modernas e industrializadas de sus respectivos países: Renania, Westfalia, HannoverBrunswick, y las ciudades inglesas de la revolución industrial. Cataluña y el País Vasco, en España; Lombardía, Toscana, Liguria y Piemonte, en Italia, fueron las principales regiones de procedencia de quienes instalaron talleres en Montevideo. Sin embargo, no fueron pocos los talleristas nacidos en regiones con menor desarrollo como Galicia, Castilla, Andalucía, Basilicata, Nápoles o Sicilia. Esta "particularidad" se comprende mejor si se considera a las comunidades étnicas, en el Río de 
la Plata, como espacios de socialización, de reproducción y desarrollo de tramas y vínculos generados en las sociedades de origen; tramas y vínculos que fueron reproducidos, rearticulados y resignificados, en ultramar. Esas redes facilitaron créditos y aprendizajes imprescindibles para quienes, carentes del acervo de otros, manifestaron una elevada intuición para los negocios.

Con mayor frecuencia de la supuesta, las historias personales desdibujan otros procesos y tránsitos no menos importantes: los movimientos migratorios previos a la epopeya transatlántica. Movimientos anuales, como el de los ligures que cruzaban a Francia y se contrataban como zafrales en época de levantar la cosecha, generando así, ingresos complementarios para el núcleo familiar. Migraciones temporales de campesinos al medio urbano, resultado de estrategias familiares que ayudaban a sobrellevar las penurias de fincas cuya producción era insuficiente para reproducir la mano de obra familiar. En los desplazamientos definitivos se emigraba de las áreas rurales a las urbanas y marítimas; de las regiones más atrasadas a las más modernas. Estos desplazamientos individuales y/o familiares implicaron, generalmente, el ingreso de buena parte de estos hombres a la actividad industrial con la consiguiente incorporación de experiencias sociales, capacitación y/o recualificación, conformando un "capital" socio-cultural que les permitió operar en el nacimiento del sector artesanal e industrial en ultramar. ${ }^{44}$

Esta perspectiva, a su vez, contrasta con los estudios realizados en los países de la Europa occidental y en Estados Unidos, donde el perfil del nuevo empresariado fabril se caracterizó por sus fuertes vínculos con los cuadros empresariales existentes, y donde la incorporación de hombres externos a esos cuadros, bien por su origen social (asalariados) como geográfico (inmigrantes) fue débil, al menos en algunas de las ramas, como la textil en Inglaterra y Francia, o la metalúrgica en Estados Unidos. Sin embargo, los registros empresariales del taller y la pequeña empresa en esos países, reconocen una fuerte presencia de inmigrantes y antiguos asalariados.45 En páginas precedentes, se ha señalado que en Argentina, Brasil y Chile se constata un proceso muy similar al uruguayo.

44 Alcides Beretta Curi, "Inmigración y aprendizajes empresariales durante la temprana industrialización del Uruguay, 1875-1914”, en Revista Theomai/Theomai Journal n. ${ }^{\circ}$, Quilmes, Universidad Nacional de Quilmes, 2001.

45 Charles Hirschman and Elizabeth Mogford, "Immigration and the American industrial revolution from 1880 to 1920", in Social Science Research nº38, 2009, pp.897-920.

Dossier: Artesanos: formas de trabajo, sociabilidades, movilidad social y cultura política en Hispanoamérica, siglos XVI-XX 


\section{Salario, ahorro y taller ${ }^{46}$}

En Montevideo, el trabajo asalariado estaba más extendido que en otras ciudades latinoamericanas, aunque sobrevivían elementos de carácter precapitalista como la remuneración del trabajo incluyendo vivienda y comida; el carácter subordinado del trabajador respecto al empleador en situaciones que no se definen claramente al estar empadronados en la vivienda del empleador. Una segunda pregunta aborda un punto capital de la investigación ¿̇cómo y en qué tiempo se constituyó el capital para la instalación de un taller en el Montevideo de la segunda mitad del XIX y la primera década y media del $\mathrm{xx}$ ?

En trabajos anteriores he abordado este tema, sobre el que aún hay escasa acumulación. Diversas fuentes y testimonios de época son coincidentes en un comportamiento social muy extendido en las diversas colectividades de inmigrantes que recalaron en Montevideo: el ahorro sobre el salario. Tanto las impresiones del viajero francés Xavier Marmier, ${ }^{47}$ llegado a Montevideo al iniciarse la década de 1850, como las del médico alemán Karl Brendel, ${ }^{48}$ veinte años más tarde, dan cuenta de este comportamiento generalizado y no estrictamente vinculado a uno de los grupos étnicos. En 1858, el médico saboyano Gabriel Sonnet -en Montevideo con funciones de agregado consular y de cultura del Reino Sardo-, se refirió a las privaciones de que era capaz un genovés por ahorrar, al punto que pasaría "todo un día sin comer para no gastar el primer dinero que le cae en mano" y apreciaba que "por poco que sea, el encuentra siempre como hacer economías". ${ }^{49}$ Francisco Piria -un representativo self-made man- apreciaba con agudeza algo que estaba a la vista de todos: a partir de cualquier desempeño asalariado muchos trabajadores hallaban el medio de ahorrar e instalarse por su cuenta: "ese limpiabotas se transformó en

46 Esta sección del artículo tiene antecedentes en trabajos anteriores: Alcides Beretta Curi, El imperio de la voluntad. Una aproximación al rol de la inmigración europea y al espíritu de empresa en el Uruguay de la temprana industrialización, 1875/1930, Montevideo, Fin de Siglo, 1996; "Inmigración y aprendizajes empresariales durante la temprana industrialización del Uruguay, 18751914", 20 pp.

47 Xavier Marmier, Buenos Aires y Montevideo en 1850, Montevideo, Arca, 1967, p.102.

48 Fernado Mañé Garzón y Angel Ayestarán, El gringo de confianza, Montevideo, 1992, pp.112113 .

49 Relación de G. Sonnet, Julio 29 de 1858: citado en Domenico Ruocco, L'Uruguay e gli italiani, Roma, Societá Geografica, 1991, p.122.

Dossier: Artesanos: formas de trabajo, sociabilidades, movilidad social y cultura política en Hispanoamérica, siglos XVI-XX 
remendón, se metamorfoseó en zapatero, y estableció casa... muchos que hoy soy propietarios de buenos establecimientos... icomenzaron lustrando botines!". 50

Ciertamente, la mano de obra cualificada contó con la posibilidad de mejores remuneraciones, respecto al resto de los trabajadores. Conocimiento, experiencia y ahorro, condujeron de la mano a soluciones laborales de independencia. La capacidad de ahorro, sin embargo, fue posible aún para muchos que carecían de cualificación y, consiguientemente, recibieron salarios bajos. Por tanto, es necesario insistir en factores no solamente económicos, sino también en los aspectos psicológicos y las dimensiones culturales, para explicar este fenómeno.

Desde la historia económica, las investigaciones desarrolladas por María Camou y Leonardo Calicchio sobre salarios y costos de vida en el Río de la Plata concurren a sostener estas apreciaciones. En Montevideo, entre 1880 y 1907, una familia de trabajadores del sector privado -compuesta por cuatro personas- invertía en alimentación un porcentaje del salario bastante próximo al de una familia similar en Europa. En el largo plazo se aprecia una diversificación de la canasta de alimentos para ese mismo período, consecuencia de una mayor oferta y variedad de productos alimenticios en el Uruguay. ${ }^{51}$ Coincidentemente, Giosué Bordoni apreciaba, hacia 1885, una mayor variedad y riqueza nutritiva de la canasta familiar básica en Uruguay respecto a Italia. ${ }^{22} \mathrm{~A}$ partir de esta canasta era posible desarrollar ciertas estrategias -según se desprende de varias memorias de empresarios-: algunos demoraban la constitución de una familia hasta contar con su taller propio; o las familias optaban por suprimir ciertos artículos del consumo familiar, o bien los sustituían por otros más económicos. Leonardo Calicchio advierte que, desde 1910, el salario real privado inició una caída acentuada, respecto al similar en Buenos Aires, que no se recuperó hasta 1921.53 Esta caída del salario real privado concurre a explicar el agotamiento de una vía de gestación de la empresa artesanal e

50 Citado en Luis Martínez Cherro, Por los tiempos de Francisco Piria, Piriápolis, Asociación de Fomento y Turismo de Piriápolis, 1990, p.36.

51 María Camou, Salarios y costos de vida en el Rio de la Plata (1880/1907). Documentos de Trabajo n. ${ }^{\circ} 28$, Montevideo, Unidad Multidisciplinaria, Facultad de Ciencias Sociales. Abril, 1996, pp.5, 9, 11.

52 Giosué Bordoni, Montevideo e la Repubblica dell'Uruguay, Milano, Fratelli Dumoladrd, 1885.

53 Leonardo Calicchio, Salario y costo de vida en el Río de la Plata (1907/1930, Documento de Trabajo n. ${ }^{\circ} 33$, Montevideo, Unidad Multidisciplinaria. Facultad de Ciencias Sociales, Julio 1996, p.23.

Dossier: Artesanos: formas de trabajo, sociabilidades, movilidad social y cultura política en Hispanoamérica, siglos XVI-XX 
industrial en Uruguay por la vía del ahorro sobre el salario, como se puede observar a partir de las historias personales y de empresas.

¿Cuáles fueron los tiempos reales de ahorro y constitución del capital de instalación? En general, las muestras utilizadas, estarían revelando su viabilidad en un tiempo relativamente breve. ${ }^{54}$

Importantes industriales de plaza, se iniciaron con modestos talleres: para concretarlos, invirtieron de cinco a diez años para acumular el capital inicial: Angel Giorello (Carcere, en Liguria, 1847) con fábrica de muebles, ${ }^{55}$ Antonio Marexiano (Borghetto, provincia de Génova, 1835-Montevideo, 1906) con fábrica de zapatos, ${ }^{56}$ Luis Ghelfi (Pontremoli, en Massa-Carrara, 1859) con fábrica de muebles..$^{57}$ En un lapso que osciló entre diez y quince años, se instalaron con establecimiento propio: los molineros Luigi Podestá (Sestri Levante, provincia de Génova, 1837). ${ }^{58}$ Nicoló Peirano (Margarita Ligure, provincia de Génova, 1853) y Aristeo Levrero (San Quirico, provincia de Génova, 1864);59 Agostino Deambrosis (Lavagna, provincia de Génova, 1838) con fábrica de velas y jabones. Los tiempos de despegue se alejaron considerablemente para otros. Superaron los quince años para una habilitación independiente -y varios de ellos permanecieron más de veinte años como asalariados-: Paolo Delucchi (Moneglio, provincia de Genova, 1840), Leopoldo Rappallini (Calice, provincia de Massa-Carrara, 1855), ${ }^{60}$ con fábrica de conservas Angelo Banfi (Lurago, provincia de cómo, 1866) con carpintería, Giovanni Gaggioni (construcciones metálicas), Angelo Pozzoli con fábrica de tejido de alambre, ${ }^{61}$ Guillermo

\footnotetext{
54 A. Beretta Curi, "Inmigración y aprendizajes empresariales durante la temprana industrialización del Uruguay, 1875-1914”.

55 El Industrial Uruguayo, Montevideo, mayo 1 de 1903.

56 Horacio Araujo Villagrán, Los italianos en el Uruguay. Diccionario biográfico, Barcelona/Paris/Milán, Escardo \& Araujo Eds., 1920.

57 H. Araujo Villagrán, Los italianos en el Uruguay.

58 H. Araujo Villagrán, Los italianos en el Uruguay.

59 H. Araujo Villagrán, Los italianos en el Uruguay.

60 El Industrial Uruguayo, Montevideo, diciembre 16 de 1905.

61 El Industrial Uruguayo, Montevideo, marzo 15 de 1903.
} 
Strauch (Hannover, 1844) con taller para elaboración de creolina. ${ }^{62}$ El taller devino, rápidamente, en un importante establecimiento.

La mayoría de los empresarios no "despegaron" de ese universo de talleristas. Es cierto que, algunos de esos establecimientos eran tan simples en su estructura y funcionamiento que permanecieron en esencia los mismos, aun cuando, más tarde, incorporaron trabajadores asalariados. Tal fue el caso de la fábrica de canastos de Pablo Berteletti; 63 la fábrica de sombreros de paja "El Progreso" del florentino Sextino Mannoci; ${ }^{64}$ el establecimiento de alfarería de José Guerra (Castelluccio, provincia de Potenza, ¿11866?);65 la fábrica de calzado "Pi-Bon" de Gaudencio del Pozzo (Bene-Vagienna, provincia de Cuneo, 1873), ${ }^{66}$ o la fábrica de mosaicos "El León". ${ }^{67}$

Las actividades vinculadas a la construcción -en una ciudad en plena expansiónrequirieron de diversos artesanos: marmolistas, yeseros, talladores, escultores en madera y en mármol, frentistas, ceramistas, vidrieros (vidrio grabado, vitralistas), artesanos en herrería artística (bronce, hierro). Fueron hombres destacados en sus oficios: Arturo Marchetti (Milán, 1886) en la realización de vitrales. Su taller fue uno de los más importantes en Montevideo, realizando obra para residencias privadas y edificios públicos, destacando los del Palacio Legislativo, Círculo Fomento de Bellas Artes, la Catedral Metropolitana, la Capilla Jackson, de una obra que supera las dos mil composiciones. ${ }^{68}$ Carlo Brignoni (Cantón Ticino) con oficio de "muratore", en Montevideo inició la producción artesanal de baldosas. ${ }^{69}$ Roque Calace

62 La Industria, Montevideo, enero 1 de 1896.

63 El Industrial Uruguayo, Montevideo, Julio 16 de 1903.

64 El industrial Uruguayo, Montevideo, Diciembre $1^{\circ}$ de 1903.

65 El industrial Uruguayo, Montevideo, Marzo 16 de 1904.

66 Libro del centenario, Montevideo, Agencia Capurro y Cia., 1925, p.816.

67 El industrial Uruguayo, Montevideo, Junio 15 de 1906.

68 H. Araujo Villagrán, Los italianos en el Uruguay.

69 El Industrial Uruguayo, Montevideo, noviembre 11 de 1905.

Dossier: Artesanos: formas de trabajo, sociabilidades, movilidad social y cultura política en Hispanoamérica, siglos XVI-XX 
(Pignola, 1860) con oficio de mosaísta, instaló un taller en $1898 .{ }^{70}$ Emilio Callegari (Spezia, 1848-Montevideo, 1915) con taller de caños de plomo. ${ }^{71}$

En la rama del tabaco, fueron muy numerosas las "cigarrerías" (talleres de picado y armado de cigarrillos), y conservaron su carácter artesanal establecimientos que adquirieron con el tiempo mayor relevancia por generar artículos de amplio consumo popular o por el contrario, elaborar habanos de calidad. El italiano Do-

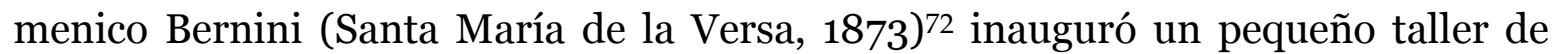
producción y venta directa. En menos de un quinquenio había incorporado el trabajo de varias mujeres en tareas de despalillado, picado, armado y empaquetado de los cigarrillos. Se asoció más tarde con Luis Montedónico (Buenos Aires, 1870?/Montevideo, 1919?), hijo de padres italianos. ${ }^{73}$ "La Republicana" del francés Jules Mailhos (Tarbes, 1855-Montevideo, 1915) fue la empresa más fuerte del sector tabacalero hacia 1910 y procesó la absorción de varias firmas importantes del ramo. Inició como un pequeño taller para picar tabaco y armar cigarrillos. ${ }^{74}$ Ramón Sánchez Nogueira (Santiago de Compostela, 1886/Montevideo, 1965) iniciador de una pequeña empresa que se especializó en la elaboración de habanos para una clientela muy selecta y exigente.

Los hermanos Juan (Génova, 1867) y Santiago Badano (Génova, 1869), llegados a Montevideo con sus padres en 1873, se iniciaron en el oficio de hojalateros luego de pasar por la Escuela de Artes y Oficios de Montevideo. Instalaron en sociedad un taller de hojalatería. ${ }^{75}$ Juan (Pallare, provincia de Génova, 1874) y Pietro Bellini (Pallare, 1884), con oficio de tornero adquirido en Italia, instalaron un pequeño taller en Montevideo a fines del XIX. ${ }^{76}$

70 Revista de Industria y Comercio, Montevideo, Mayo de 1932.

71 H. Araujo Villagrán, Los italianos en el Uruguay.

72 El industrial Uruguayo, Montevideo, Febrero $1^{\circ}$ de 1906.

73 Entrevista: María Catalina Montedónico, sobrina de Luis Montedónico; entrevista realizada: 22/12/1995.

74 Alcides Beretta Curi, Inmigración europea e industria. Uruguay en la región, 1870-1915, Montevideo, CSIC/Universidad de la República, 2014.

75 H. Araujo Villagrán, Los italianos en el Uruguay.

76 H. Araujo Villagrán, Los italianos en el Uruguay.

Dossier: Artesanos: formas de trabajo, sociabilidades, movilidad social y cultura política en Hispanoamérica, siglos XVI-XX 
En los ramos del vestido y calzado, proliferó un gran número de talleres. Juan Rodríguez Rial (España, 1866 ¿̇?), desde 1881 en Montevideo. En 1905 inició un taller de corsés y camisas que tenía su origen en el trabajo de su esposa como costurera a domicilio para empresas de ropas. ${ }^{77}$ Sextino Mannoci (Florencia, ¿̇?), llegó a Buenos Aires en 1894 y dos años más tarde instaló taller de sombreros en Montevideo. ${ }^{78}$ Juan Ballester (Mallorca, 1866), abrió taller de calzado de calidad para señoras; ${ }^{79}$ Luis Bartoli (Massa-Carrara, 1856 ) se formó junto a su padre como zapatero y una vez en Montevideo instaló un taller de calzado.

En la rama metalúrgica: Antonio Duñach (Gerona), emigró a Buenos Aires en 1877 y a Montevideo desde 1888. Adquirió oficio de herrero y en 1893, en sociedad con N. Galletti, instala una herrería artística que devino en un importante establecimiento. ${ }^{80}$ Juan Gaggioni (Cortemiglia, Provincia de Cúneo, 1833-Montevideo, 1904), en Uruguay desde 1868. Abrió taller mecánico en 1887 y abordó emprendimientos mayores al ampliar el local. ${ }^{81}$

Otros casos en muy diversas actividades, serán suficientes para presentar este amplio espectro de talleres artesanales en el Montevideo de la primera modernización: Fernando Begh (Gerona, 1873) con elaboración de conservas alimenticias; Pablo Berteletti (Turín ¿ं?), en Montevideo desde 1897: pertenecía a una familia con larga tradición en plantar y trabajar el mimbre de Borgoña, inició un taller que producía canastas. ${ }^{82}$ Eulogio Voces Calvo (Villafranca del Bierzo/Provincia de León/España, 1891) luego de trabajar en Buenos Aires se instala en Montevideo con un taller que producía máquinas para café y balanzas para almacenes. ${ }^{83}$ Luigi Tammaro (Nápoles, 1854-Montevideo, 1912). Llegó a Montevideo en 1887, con profesión grabador. Instaló un taller de grabado y medallas, que devino el más impor-

77 El Industrial Uruguayo, Montevideo, julio 30 de 1906.

78 El Industrial Uruguayo, Montevideo, diciembre 1 de 1903.

79 Luis Valls y Jaime Moragues, Los españoles del Uruguay, Montevideo, 1918.

80 El Industrial Uruguayo, Montevideo, junio 1 de 1908.

81 Revista de Industria y Comercio, Montevideo, enero de 1931.

82 El Industrial Uruguayo, Montevideo, julio 16 de 1903.

83 Revista de Industria y Comercio, Montevideo, Mayo de 1932.

Dossier: Artesanos: formas de trabajo, sociabilidades, movilidad social y cultura política en Hispanoamérica, siglos XVI-XX 
tante del ramo. ${ }^{84}$ Giuseppe Tucci (Acri, Potenza, 1884). En Montevideo abrió taller para fabricar mesas para billar. ${ }^{85}$

La nómina puede prolongarse, recreando situaciones similares que articulan la condición de inmigrante y artesano.

\section{Conclusiones}

El artesanado tuvo un débil desarrollo en Montevideo, durante el período colonial, si tenemos en cuenta su tardía y breve historia. Una sociedad carente de rígidas estructuras sociales, pequeña en su composición numérica: Montevideo tenía unos 14.00o habitantes y menos de 80.000 la población del Uruguay, cuando éste se constituyó como Estado independiente en 1828. La importancia de la capitalpuerto y el creciente vínculo al mercado internacional, concurrieron en su mayor desarrollo pese a la pervivencia de elementos precapitalistas.

La independencia no implicó la desarticulación de la estructura gremial, prácticamente inexistente, y el artesanado se desarrolló acompañando un proceso de crecimiento económico y demográfico, y de expansión urbana hacia fines de la década de 1860. El "alud inmigratorio" europeo impactó sobre la sociedad montevideana, moldeándola profundamente, enriqueciéndola culturalmente y modificando las pautas de consumo. Las crisis económicas y financieras, las necesidades recaudatorias de un Estado endeudado, fueron claves en definir una política proteccionista para las "industrias" $(1875,1886,1888)$, de modo que el incremento de la demanda interna y proteccionismo favorecieron la multiplicación de talleres y aparecieron las primeras fábricas.

En la base del desarrollo de un sector artesano-industrial se conjugaron varios factores principalísimos: a) la inmigración masiva que aportó cuadros con formación en oficios, habilidades y destrezas, así como experiencia industrial; b) un capital cultural que aportó la inmigración en cuanto a una mentalidad abierta, racional, moderna que, junto a un código de valores -reconocimiento del trabajo como vir-

84 Actualmente, la empresa no emplea más de 10 operarios, y conserva el trabajo artesanal de los inicios.

85

H. Araujo Villagrán, Los italianos en el Uruguay.

Dossier: Artesanos: formas de trabajo, sociabilidades, movilidad social y cultura política en Hispanoamérica, siglos XVI-XX 
tud, ahorro, esfuerzo personal y aspiración de ascenso social- fueron funcionales al programa modernizador de la elite gobernante y al desarrollo del capitalismo. En esta perspectiva, Uruguay presenta un perfil singular en la América Latina, con fuertes afinidades a las experiencias de otras sociedades del sur americano como Argentina, Brasil y Chile.

\section{Bibliografía}

\section{Archivos}

Archivo La Republicana

Archivo Dr. Sergio Abal Bonomi

\section{Fuentes editadas}

“Anuario Estadístico del Uruguay”, Censo de 1908, Montevideo, 1909.

Bordoni, Giosué Montevideo e la Repubblica dell'Uruguay, Milano, Fratelli Dumoladrd, 1885 .

Marmier, Xavier, Buenos Aires y Montevideo en 1850, Montevideo, Arca, 1967, 79 pp.

\section{Diccionarios biográficos}

Araujo Villagrán, Horacio Los italianos en el Uruguay. Diccionario biográfico, BarcelonaParis/Milán, 1920.

Valls, Luis y Moragues, Jaime, Los españoles del Uruguay, Montevideo, 1918.

\section{Historiografía:}

Abramson, Pierre-Luc, Las utopías sociales en América Latina en el siglo XIX, México, Fondo de Cultura Económica, 1999, 407 pp.

Beretta Curi, Alcides, "Inmigración y aprendizajes empresariales durante la temprana industrialización del Uruguay, 1875-1914”, en Revista Theomai/Theomai Journal n. ${ }^{\circ}$, Quilmes, Universidad Nacional de Quilmes, 2001. 
Beretta Curi, Alcides, "Del artesanado a los gremios industriales. Liberalismo y tensiones en la constitución de las primeras asociaciones patronales. El caso de la Liga Industrial (1879-1888)", en Revista de Ciencias Sociales, segunda época, n. ${ }^{\circ}$ 24, Quilmes, Universidad Nacional de Quilmes, 2013, pp.87-108.

Beretta Curi, Alcides, Inmigración europea e industria. Uruguay en la región (1870-1915), Montevideo, Universidad de la República, 2014, 160 pp.

Beretta Curi, Alcides, El imperio de la voluntad. Una aproximación al rol de la inmigración europea y al espíritu de empresa en el Uruguay de la temprana industrialización, 1875/1930, Montevideo: Fin de Siglo, 1996.

Beretta Curi, Alcides, "Emigración italiana y modernización en la periferia. Los italianos en la creación del sector industrial uruguayo (1870/1930)", en Studi Emigrazione n. ${ }^{\circ}$ 150, Roma, Centro Studi Emigrazione, 2003, pp.227-251.

Beretta Curi, Alcides, "L'immigrazione europea nella formazione del tessuto imprenditoriale: l'Uruguay e le nazioni circostanti (1870-1900)", en Studi-Emigrazione vol. XVIII, n. ${ }^{\circ}$ 184, Roma, Centro Studi Emigrazione, 2011, pp.675-695.

Bentancur, Arturo, El Puerto colonial de Montevideo, Montevideo, Facultad de Humanidades y Ciencias de la Educación, 2 tomos, 1998-1999.

Cagiao Vila, Pilar, "La inmigración gallega en Uruguay (1870-1936)”, en Anuario Americanista Europeo $\mathrm{n}^{\mathrm{O}} 3$, Salamanca, Redial/Cesial, 2005, pp.93-112.

Calicchio, Leonardo, Salario y costo de vida en el Río de la Plata (1907/1930, Documento de Trabajo n. ${ }^{\circ} 33$, Montevideo, Unidad Multidisciplinaria. Facultad de Ciencias Sociales, Julio 1996.

Camou, María, Salarios y costos de vida en el Rio de la Plata (1880/1907). Documentos de Trabajo n. ${ }^{\circ}$ 28, Montevideo, Unidad Multidisciplinaria, Facultad de Ciencias Sociales. Abril, 1996.

Camou, María y Pellegrino, Adela, "Una fotografía instantánea de Montevideo”, en Ediciones del V Centenario, tomo 2, Montevideo, Universidad de la República, 1992, pp.135-136.

Caraballo, Dahiana y Sagaseta, Graciana, "Los aportes de los Sistemas de Información Geográfica en la investigación histórica. El sector de la madera y el calzado en Montevideo a fines del siglo XIX”, (trabajo monográfico realizado en el seminario de investigación "Inmigración europea y artesanado: entre la protesta popular y los primeros programas industrialistas en América Latina (1870/190o)" segundo semestre de 2012 (Centro de Estudios Interdisciplinarios Latinoamericanos Profa. Lucía Sala" (CEIL) Facultad de Humanidades y Ciencias de la Educación, Universidad de la República. 
Carbajal Arenas, Lilia, "Los artesanos de Puebla y el arancel de 1821”, en Análisis Económico vol. XXVIII, n. ${ }^{6}$ 68, México D. F., UAM-Azcapotzalco, 2013, pp.135-154.

Dean, Warren, "Industriales y oligarquía en el desarrollo de San Pablo," en Mario Cerutti, y Menno Vellinga (comps.), Burguesías e industria en América Latina y Europa meridional, Madrid, Alianza Ed., 1989, pp.23-54.

Epstein, S. R., Prak Maarten, Guilds, Innovation, and the European Economy, 140o180o, New York, Cambridge University Press, 2008.

Estrada Turra, Baldomero, "Participación italiana en la industrialización de Chile. Orígenes y evolución hasta 1930”, en Baldomero Estrada Turra (ed.), Presencia italiana en Chile, Serie Monografías Históricas, n. ${ }^{\circ}$, Valparaíso, Universidad Católica de Valparaíso, 1993, pp.89-123.

Navarro Azcue, Concepción y Estrada Turra, Baldomero, "Migración y Redes de poder en América: el caso de los industriales españoles en Valparaíso (Chile) 1860-1930", en Revista Complutense de Historia de América vol.31, Madrid, Universidad Complutense, 2005, pp.115-146.

Farías, Ruy, "Peones, obreros y jornaleras: Patrones de asentamiento e inserción socioprofesional de los gallegos en Avellaneda y Lanús, 1890-1930”, en Buenos Aires Gallega. Inmigración, pasado y presente, Buenos Aires, Comisión para la Preservación del Patrimonio Cultural de la Ciudad Autónoma de Buenos Aires, 2007.

Favero, Luigi, et al, Il contributo italiano allo sviluppo del Cile, Torino, Fondazione Giovanni Agnelli, 1993, 470 pp.

Flórez Bolívar, Roicer y Solano, Sergio Paolo, "Educando al buen ciudadano. Las guardias nacionales en la Provincia de Cartagena, Colombia, 1832-1857”, en Anuario de Estudios Americanos, vol.67, n. ${ }^{\circ}$ 2, Sevilla, EEHA, 2010, pp.605-633.

Flórez Bolívar, Roicer, Solano, Sergio Paolo y Álvarez Jiménez, Jairo, "Liberalismo, ciudadanía y vecindad en Nueva Granada (Colombia) durante la primera mitad del siglo XIX”, en Tempo n. ${ }^{\circ} 32$, Rio de Janeiro, Universidade Federal Fluminense, 2012, pp.163-192.

Gallo, Ezequiel, "Política y sociedad en Argentina, 1870-1916”, en Lesli Bethell (ed.), Historia de América Latina. 10 América Latina: economía y sociedad, c. 1870-1930, Barcelona, Ed. Crítica, 1991, pp.41-66.

García-Bryce, Iñigo, "Politics by Peaceful Means: Artisan Mutual Aid Societies in MidNineteenth-Century Lima, 1860-1879", in The Americas vol.59, n. ${ }^{\circ} 3$, Washington, D. C., Academia Histórica de la Orden Franciscana, 2003, pp.325-345.

Gazmuri, Cristián, El 48 chileno, Santiago, Ed. Universitaria, 1998, 215 pp. 
Gootenberg, Paul, "The Social Origins of Protectionism and Free Trade in NineteenthCentury Lima”, in Journal of Latin American Studies, vol.14, n. ${ }^{\circ}$, Durham, Duke University, 1982, pp.329-358.

Grez Toso, Sergio, "La reivindicación proteccionista artesanal y la constitución del movimiento popular (Chile, 1826-1855)", en Historia Social n. ${ }^{\circ} 31$, Valencia, Instituto de Historia Social, 1998, pp.89-99.

Grez Toso, Sergio, "Los artesanos chilenos del siglo XIX: un proyecto modernizadordemocratizador", en Cyber Humanitatis n. ${ }^{\circ}$ 41, Santiago de Chile, Universidad de Chile, 2007. www.archivochile.com/Ideas_Autores/grezs/grezso019.pdf.

Hirschman, Charles and Mogford, Elizabeth, "Immigration and the American industrial revolution from 1880 to 1920", in Social Science Research n³8, 2009, pp.897-920.

Illanes, M. A., "La revolución solidaria. Las sociedades de socorros mutuos de artesanos y obreros: un proyecto popular democrático, 1840-1887", en Polis vol.1, n. ${ }^{\circ}$ 5, Santiago de Chile, Universidad Bolivariana, 2003, pp.1-63.

Jacob, Raúl, Breve historia de la industria uruguaya Montevideo, Fundación de Cultura Universitaria, 1981, $155 \mathrm{pp}$.

Jaramillo Uribe, Jaime, "Las sociedades democráticas de artesanos y la coyuntura política y social colombiana de 1848", en Anuario Colombiano de Historia Social y de la Cultura n. ${ }^{\circ} 8$, Bogotá, Universidad Nacional, 1976, pp.5-18.

Lida, Clara E., “Trabajo, organización y protesta artesanal: México, Chile y Cuba en el siglo XIX”, en Historia Social n. ${ }^{\circ}$ 31, Valencia, Instituto de Historia Social 1998, pp.67-75.

López Monjardin, Adriana, "El artesano urbano a mediados del siglo XIX”, en Anuario II, Veracruz, Universidad Veracruzana, 1979, pp.55-63.

Marmier, Xavier, Buenos Aires y Montevideo en 1850, Montevideo, Arca, 1967.

Mañé Garzón, Fernado y Ayestarán, Angel, El gringo de confianza, Montevideo, 1992.

Martínez Cherro, Luis, Por los tiempos de Francisco Piria, Piriápolis, Asociación de Fomento y Turismo de Piriápolis, 1990

Melo, Jorge Orlando, "La evolución económica de Colombia, 1830-1900", en Manual de Historia de Colombia, tomo 2, Bogotá, Instituto Colombiano de Cultura, 1979, pp.133-207.

Millot, Julio y Bertino, Magdalena, Historia económica del Uruguay, tomo II 186o-191o, Montevideo, FCU, 1996, 470 pp. 
Oddone, Juan A., "Italians in Uruguay: Political Participation and Country Consolidation during Mass Immigration", in The Columbus People: Perspectives in Italian Immigration to the Americas and Australia Wiley Online, vol.11, n. ${ }^{\circ}$, Library Special 1994.

Oddone, Juan A., La Emigración Europea al Río de la Plata, Montevideo, Eds. de la Banda Oriental, 1966, $112 \mathrm{pp}$.

O’Rourke, Kevin H. y Williamson, Jeffrey G., Globalización e historia: la evolución de la economía atlántica en el siglo XIX, Zaragoza, Prensas Universitarias de Zaragoza, 2006.

Orduña Carson, Miguel, "Artesanos de la ciudad de México en la segunda mitad del siglo XIX: luchas de resistencia en el marco de la hegemonía”, en Travesía n. ${ }^{\circ} 10-11$, San Miguel de Tucumán, Universidad Nacional de Tucumán, 2008-2009, pp.101-120.

Pérez Toledo, Sonia, "Una organización alternativa de artesanos: la Sociedad Mexicana Protectora de Artes y Oficios, 1843-1844", en Signos Históricos n. ${ }^{\circ}$ 9, México D. F., UAM-Iztapalapa, 2003, pp.73-100.

Pérez Toledo, Sonia, Los hijos del trabajo. Los artesanos de la ciudad de México, 17801853, México D. F., Universidad Autónoma Metropolitana/El Colegio de México, 1996, $300 \mathrm{pp}$.

Pérez Toledo, Sonia y Illades, Carlos, "el artesanado textil de la ciudad de méxico durante el siglo XIX", en Historia Social n. ${ }^{\circ} 31$, Valencia, Instituto de Historia Social, 1998, pp.77-88.

Pierrotti, Nelson, "La enseñanza de los oficios en el Montevideo colonial (1726 - 1830)", en Páginas de Educación vol.2, n. ${ }^{\circ}$ 2, Montevideo, Universidad Católica de Uruguay, 2009, pp.115-134.

Rodríguez Villamil, Silvia y Sapriza, Graciela, La inmigración europea en el Uruguay. Los italianos, Montevideo, Eds. de la Banda Oriental, 1982, 150 pp.

Ruocco, Domenico, L’Uruguay e gli italiani, Roma, Societá Geografica, 1991.

Sala, Lucía, Torre, Nelson de la y Rodríguez, Julio Carlos, Estructura económico-social de la colonia, Montevideo, Eds. Pueblos Unidos, 1967, pp.137-140.

Salazar, Gabriel, "Industrialización popular en Chile: perfil del empresariado plebeyo (1823-1885)", en Encuentros Latinoamericanos vol.vi, $\mathrm{n}^{0}{ }^{\mathrm{1}}$, Montevideo, Universidad de la República, 2012, pp.129-171.

Sánchez-Albornoz, Nicolás, "La población de América Latina, 1850-1930", en Lesli Bethell (ed.), Historia de América Latina. 7 América Latina: economía y sociedad, c. 1870-1930, Barcelona, Ed. Crítica, 1991, pp.112-113. 
Schultz, Helga, Historia económica de Europa, 150o-18oo. Artesanos, mercaderes y banqueros, Madrid, Siglo XXI, 2001.

Solano, Sergio Paolo, "El mundo del trabajo urbano en el Caribe colombiano durante el siglo XIX”, en José Polo y Sergio Paolo Solano (eds.), Historia social del Caribe colombiano, Medellín, Universidad de Cartagena/La Carreta Editores, 2011, pp.73122.

Solimano, Andrés, "Migraciones internacionales y mercado de trabajo globalizado: la experiencia latinoamericana", en Revista de la CEPAL n. ${ }^{\circ} 80$, Santiago de Chile, Cepal, 2003, pp.55-72.

Trujillo Bolio, Mario, Empresariado y manufactura textil en la ciudad de México y su periferia, México D. F., Siglo XIX/CIESAS, 2000.

Urta, Gimena, “Artesanos, comerciantes y los orígenes de la industria (1830-1860)”, versión borrador del trabajo preparado en el seminario de investigación del Centro de Estudios Interdisciplinarios Latinoamericanos "Profa. Lucía Sala", Facultad de Humanidades y Ciencias de la Educación, Universidad de la República.

Vania, Herédia, O processo de industrialização da zona colonial italiana: estudo de caso da primeira indústria têxtil do Nordeste do estado do Rio Grande do Sul, Caxias do Sul, Universidade de Caxias do Sul, 1997, 240 pp.

Vega Cantor, Renán, “Liberalismo económico y artesanado en la Colombia decimonónica”, en Boletín Cultural y Bibliográfico vol.XXVII, n. ${ }^{\circ} 22$, Bogotá, Biblioteca Luís Ángel Arango, 1990, pp.47-65. 